\title{
A case of labio-facial necrotizing fasciitis complicating acne
}

\author{
Amel Salah Eltayeb ${ }^{1 *}$, Abdelnasir Gafar Ahmad ${ }^{1}$ and Elnour Ibrahim Elbeshir ${ }^{2}$
}

\begin{abstract}
Background: Facial necrotizing fasciitis is extremely rare. Most of the cases reported in literature are related to dental, sinus, tonsillar and salivary glands causes, but rarely as consequence of skin infection. We report a unique case of lower lip cellulitis, which was initially misdiagnosed as angioedema and subsequently progressed into lower lip necrotizing fasciitis.

Case presentation: This is a case report of necrotizing fasciitis involving the lower lip as a consequence of infected skin acne in a 19 year old black female. The patient had been diagnosed earlier as a case of angioedema by a physician and treated accordingly. She was mildly anemic, hyponatremic and hypokalemic. Treatment was started immediately by incision, drainage and full debridement of the whole necrotic tissue. Triple antibiotic therapy was administered and daily irrigation and dressing were performed until full recovery. Complete healing occurred within a month by secondary intention.
\end{abstract}

Conclusion: This case demonstrates the misdiagnosis of a lip swelling leading to the development of labiofacial necrotizing fasciitis, a serious and life threatening condition. Lip angioedema is a common condition; however, lip fasciitis is rare. A broad differential diagnosis in case of lower lip swelling is essential to avoid inappropriate treatment delay.

Keywords: Necrotizing fasciitis, Lower lip, Angioedema

\section{Background}

Necrotizing fasciitis (NF) is a rare but potentially fatal infection [1]. Its rapid and destructive clinical course is assumed to be caused by polymicrobial symbiosis and is usually associated with immunocompromised status such as cancer, diabetes mellitus, vascular insufficiencies, organ transplantation and alcohol abuse [2]. It most commonly presents in the extremities [leg $33 \%$ and hand $7.5 \%$ ] [3], trunk, genitalia and perineum (20.2 \%) [4]. In the head and neck region, cervical necrotizing fasciitis is rare (5.3\%) [5] but when it does occur, dental infection is a frequent cause [6]. Cervical necrotizing fasciitis is characterized by cutaneous necrosis, suppurative fasciitis, thrombosis of small blood vessels in the subcutaneous tissue, and extreme systemic toxicity. It is a severe condition with a high risk of death [7], and is aggravated by

\footnotetext{
*Correspondence: moly71090@gmail.com

1 Khartoum Teaching Dental Hospital, P.O box 122, Khartoum, Sudan

Full list of author information is available at the end of the article
}

spread of the infection through the fasciae, with development of mediastinitis and septic shock. Deformity of the face and submandibular area is a frequent complication [8].

Facial NF is extremely rare. In 1997 Shindo et al. found only 35 reports of facial NF in their review [9]. The source of facial necrotizing fasciitis infection is either dental, sinus, peritonsillar or salivary gland infections. Infections secondary to surgery or trauma have also been reported as causative factors. Group A beta-hemolytic streptococci and staphylococci have classically been described as the causative agents, and obligate anaerobic bacteria have also been included [10]. Lip swellings are commonly diagnosed as angioedema; Bruno et al. reported a case of lung pneumonia as the consequence of a lower lip abscess which was mistakenly diagnosed as angioedema [11]. Also, Lee et al. reported a case of facial NF as the consequence of a facial wound over the upper lip, but not involving the lip itself [12].We report a unique case 


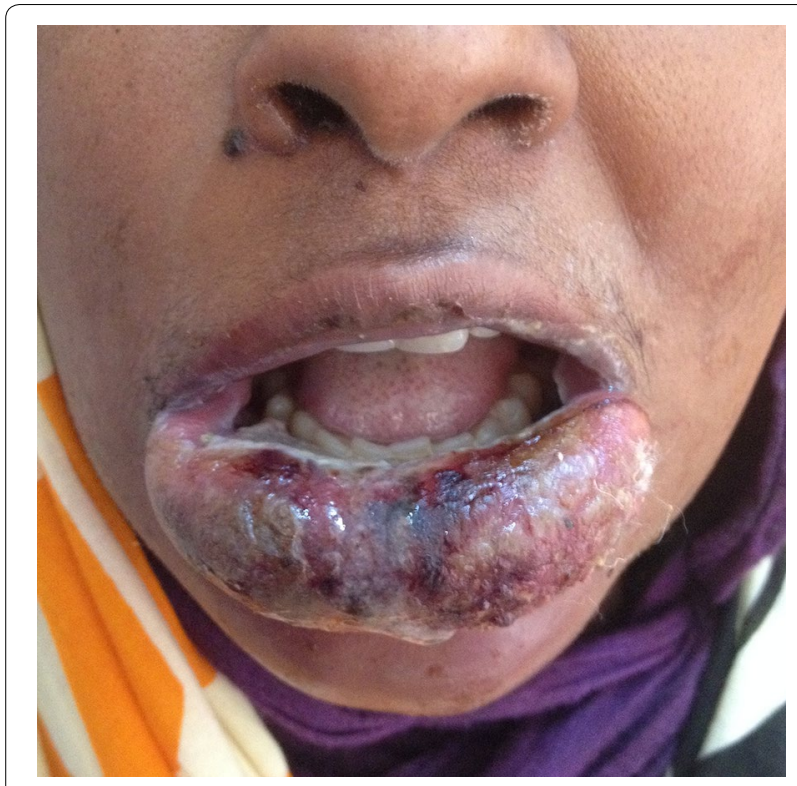

Fig. 1 Patient with painful lower lip swelling

of lower lip cellulitis, which was initially misdiagnosed as angioedema and subsequently progressed to lower lip necrotizing fasciitis.

\section{Case presentation}

A 19-year-old black female presented with painful lower lip swelling of 2 weeks duration. She was initially seen by a physician whom she claimed had given her antiallergic medication and painkillers in the form of tablets for 1 week, but the situation worsened and the swelling and pain increased. She was then prescribed intravenous penicillin for another week with no improvement, after which she presented to our hospital for assessment and further management. There was lower lip swelling with discharge from the exfoliated crusted lower lip surface. The condition had started as a small pimple on her chin just below the lower lip on the left side which was painful and increasing in size. She attempted to open it and did not use any antibiotic. After $48 \mathrm{~h}$ she became febrile and her lower lip became swollen. She went first to a physician, then presented to our dental hospital. The patient's medical and family history was non-contributory, and there was no history of trauma, hospitalization or current medication except those prescribed by the physician. She was lactating and had a 6 month old boy.

The patient's oral cavity was examined carefully and good oral hygiene was noted. There were no obvious odontogenic causes or lip paraesthesia. Panoramic radiograph was done to exclude odontogenic causes and was insignificant. A thorough facial examination followed and a small crusted pimple was noticed on the left side of the chin. There was extensive swelling involving the whole lower lip and extending to involve the chin and submental area (Fig. 1) with pus discharging from the left side of the chin just beneath the site of the pimple (Fig. 2). The patient's blood investigations were negative for HIV and hepatitis, with a TWBC of $(25.8 \times)$, random blood glucose of $190 \mathrm{mg} / \mathrm{dl}$ and a creatinine of $0.7 \mathrm{mg} / \mathrm{dl}$. She was anemic $(10 \mathrm{~g} / \mathrm{dl})$, mildly hyponatremic $(134 \mathrm{mmol} / \mathrm{l})$ and hypokalemic $(2.5 \mathrm{mmol} / \mathrm{l})$. Potassium correction was started within travenous potassium chloride at $10 \mathrm{meq} / \mathrm{l}$ over $4 \mathrm{~h}$ for 1 day, after which she was shifted to diet supplements. Normal saline $500 \mathrm{ml} /$ day was given for 2 days, as well as ferrous sulphate tablets. Electrolyte and blood levels were back to normal after 6 days $(\mathrm{K}=3.5 \mathrm{mmol} / \mathrm{l}$, $\mathrm{Na}=137 \mathrm{mmol} / \mathrm{l}$ and $\mathrm{Hb}=12 \mathrm{~g} / \mathrm{dl}$.

Based on the history and clinical presentation, the diagnosis of necrotizing fasciitis was made and a swab of the site was taken for culture and sensitivity. Treatment started with lower lip debridement and exploration where necrosis of the middle part of the lower lip was noted. A segment of necrotic fascia on the left side of the chin was found and removed with preservation of the overlying skin except over the acne-affected area where skin was removed (Fig. 3). Multiple mental and submental incisions were made for drainage. Irrigation with normal saline was done and corrugated rubber drains were inserted and secured. The patient was admitted to the hospital where intravenous fluids and an empirical triple antibiotic regimen were started immediately (Ceftazidime $1 \mathrm{Gm} /$ day, Metronidazole $500 \mathrm{mg} 8$ hourly and Gentamycin $80 \mathrm{mg} /$ day), and continued after culture and sensitivity results revealed no microbial growth. After 3 days, further tissue necrosis was noticed, so a second debridement was done with consequent tissue loss over the middle upper surface of the lower lip. Additionally, irrigation with hydrogen peroxide followed by normal saline wash was performed. Ten days later, dramatic improvement was seen, where only the Gentamycin was stopped and irrigation was continued with normal saline and topical application of Tetracycline ointment for 7 days. The drain was removed on day 19 and the patient was discharged on the 20th day on oral antibiotics for another week. On follow up, the wound showed good healing by secondary intention and there was no need for reconstruction (Fig. 4).

\section{Discussion}

Necrotizing fasciitis is an infection of the deeper tissues that results in progressive destruction of muscle fasciae and overlying subcutaneous fat. The muscle tissue itself is frequently spared because of its generous blood supply [13]. 


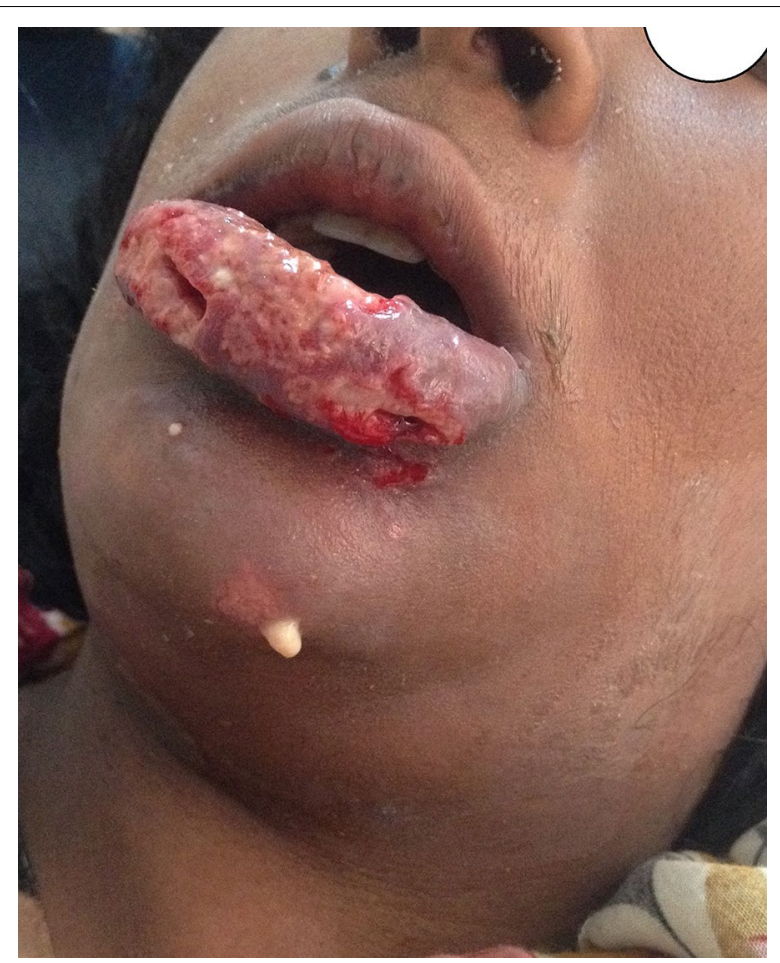

Fig. 2 Sinus discharging pus at the left side of chin

A definitive diagnosis of NF is established surgically with visualization of fascial planes and subcutaneous tissue. However, clinical clues and diagnostic tools should be used in combination to help make an early diagnosis [1]. The clinician must be highly suspicious regarding any patient presenting with a rapidly spreading swelling, erythema and fever with palpation of the wound to check for crepitus which may indicate subcutaneous gas production. The LRINEC score (Laboratory Risk Indicator for Necrotizing Fasciitis) was developed by Wong et al. to detect early cases of NF clinically. The variables used are routinely measured to assess severe soft tissue infections. Patients with a LRINEC score of $>6$ should be carefully evaluated for the presence of necrotizing fasciitis [14]. A LRINEC score of 7 was detected in our patient (excluding $\mathrm{C}$ reactive protein which was not done due to financial issues) which was suggestive of NF before surgical exploration was started.

Treatment of NF consists of early and aggressive debridement of necrotic tissue, together with broadspectrum antibiotics and fluids support. It is important to mention that NF can progress in an insidious manner and by the time it has been diagnosed the condition would have progressed to a late stage. In this patient's case, immediate surgical debridement of the whole necrotic tissue deep to the orbiculariousor is muscle was

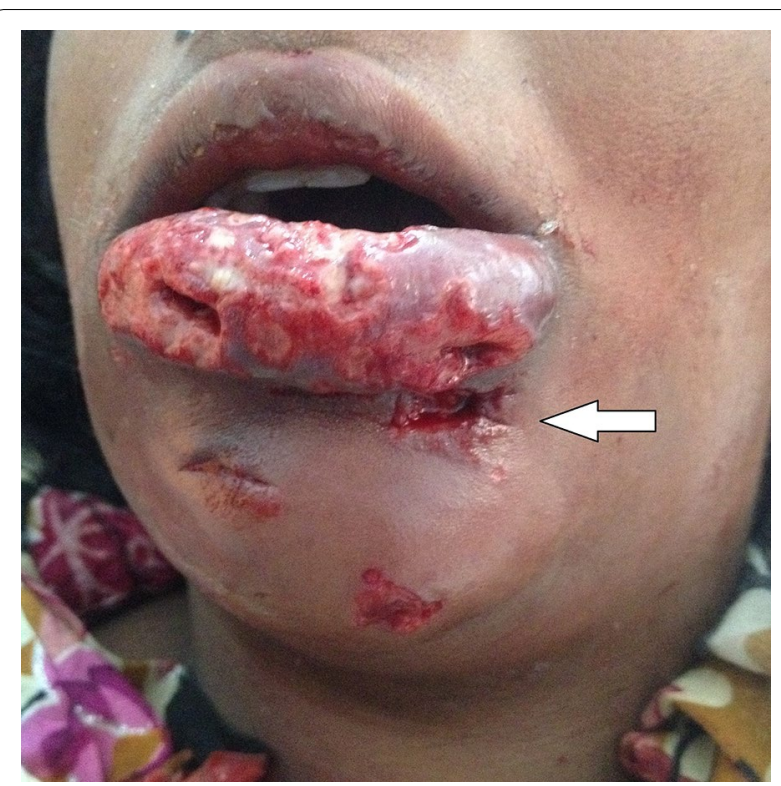

Fig. 3 Surgical debridement and multiple skin incision

done until healthy tissue was visible. Extensive fasciotomy with exposure and exploration of all involved compartments was done. Absence of growth in culture and sensitivity results could be explained by the effect of the antibiotics prescribed before she presented to the hospital. Daily dressing was performed and debridement was kept to the minimum essential to minimize the lip defect that might result from generous tissue removal.

Patients with NF usually have an associated systemic condition such as diabetes mellitus, arteriosclerosis, obesity, metastatic neoplasm, old age, hypothyroidism, alcoholism, neoplasms, cirrhosis, drug abuse, poor nutritional state, or use of corticosteroids [8]. In our case the patient was only mildly anemic and malnourished; factors that most likely predisposed to necrotizing fasciitis. Therefore, other therapeutic considerations were included to manage the hyponatremia and hypokalemia. Multivitamins were prescribed in order to improve the patient's general health. Anemia was treated by oral supplements. Hemolysis of erythrocytes may occur as a result of the actions of bacterial enzymes, resulting in anemia that may require transfusion.

Facial NF is generally due to a dental or pharyngeal abscess (surgical or post-traumatic), radiotherapy, or an unknown cause [8]. Lower lip NF is rare, but lip cellulitis as a result of chin acne infection is common especially in young adults. In the present case, it was initially misdiagnosed as angioedema. Such diagnosis resulted in the inappropriate management and delayed the proper treatment. 


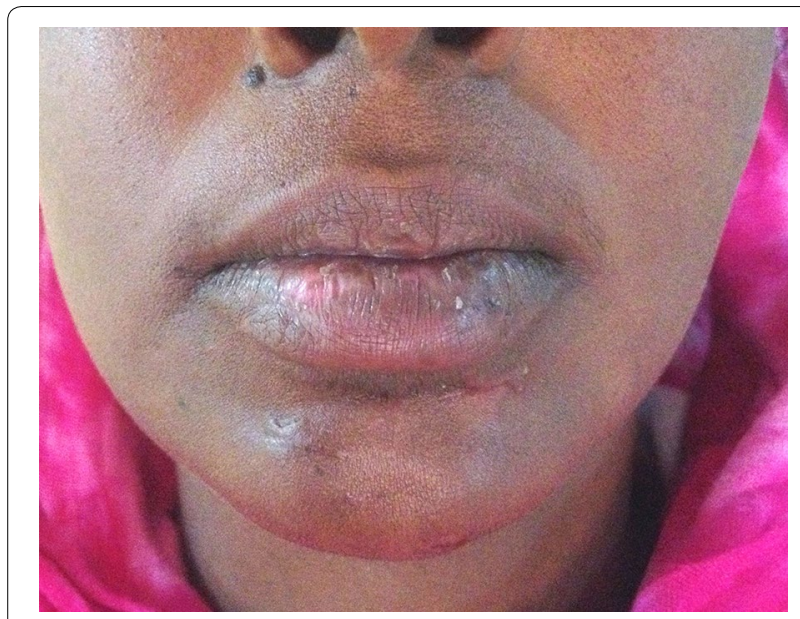

Fig. 4 Patient appearance 4 months postoperatively

\section{Conclusion}

This case illustrates a consequence of misdiagnosis of NF. When confronted with lip swelling the clinician must consider the broad spectrum of differential diagnoses and consider a developing NF on the list. Triple antibiotic therapy, investigations, correction of deficiencies, dressing and debridement are essential components of the proper management of NF.

\section{Abbreviations}

NF: necrotizing fasciitis; HIV: human immunodeficiency virus; TWBC: total white blood cell; K: potassium; Na: sodium; Hb: hemoglobin; LRINEC: Laboratory risk indicator for necrotizing fasciitis.

\section{Authors' contributions}

ASE analyzed and interpreted the patient data regarding the neoformation and general diseases. ASE and AGA were major contributors in writing the manuscript. EIE and AGA did the critical review, corrected the intellectual content and gave final approval for submission. All authors read and approved the final manuscript.

\section{Author details}

${ }^{1}$ Khartoum Teaching Dental Hospital, P.O box 122, Khartoum, Sudan.

${ }^{2}$ Faculty of Dentistry, The University of Medical Sciences and Technology, P.O Box 12810, Khartoum, Sudan.

\section{Acknowledgements}

We would like to thank all house officers and medical staff in Khartoum Teaching Dental Hospital who were involved in treating this patient.

\section{Availability of supporting data}

The data supporting the results of this article is included within the article.

\section{Competing interests}

The authors declare that they have no competing interests.

\section{Consent for publication}

Written informed consent was obtained from the patient for publication of this case report and accompanying images.

\section{Ethical approval and consent to participate}

Ethical approval was obtained from the research ethical committee of Khartoum dental teaching hospital.

\section{Funding}

No funding was obtained for this study.

Received: 10 November 2015 Accepted: 14 April 2016

Published online: 23 April 2016

\section{References}

1. Morgan MS. Diagnosis and management of necrotizing fasciitis: a multiparametric approach. J Hosp Infect. 2010;75:249-57.

2. Nissar S. Necrotizing fasciitis: a decade of surgical intensive care experience. IJCCM. 2006;10(4):225-9.

3. Balcerak RJ, Sisto JM, Bosac R. Cervical necrotizing fasciitis: report of three cases and literature review. J Oral Maxillofacial Surgery. 1988;46:450-9.

4. Deowall CC, et al. necrotizing fasciitis of the head and neck: a report of two patients and review. Head Neck. 2002;24:497-501.

5. Carter LM, Layton S. Cervicofacial infection of dental origin presenting to maxillofacial surgery units in united kingdom: a national audit. Br Dent J. 2009;206:73-8.

6. Sikkermath SB, Sikkermath BC. CNF; The flesh eating disease: review of literature and report of 5 cases. J Indian Aca Oral Med Radiol. 2013;25(2):131-6.

7. Ferri E, lanniello F, Salandin S. Necrotizing fasciitis of the neck in a patient with acute myeloid leukemia: clinical features, therapeutic strategy and review of the literature. Acta Otorhinolaryngol Ital. 1998;18:116-22.

8. Zilberstein $B$, et al. Cervical necrotizing fasciitis due to bacterial tonsillitis. Clinics. 2005;60(2):177-82.

9. Shindo ML, Nalbone VP, Dougherty WR. Necrotizing fasciitis of the face. Laryngoscope. 1997;107(8):1071-9.

10. Banerjee AR, Murty GE, Moir AA. Cervical necrotizing fasciitis: a distinct clinicopathological entity? J Laryngol Otol. 1996;110(1):81-6.

11. Bruno GJ, Bruno JM, Moir AA. Community-acquired methicillin-resistant Staphylococcus aureus infection with fatal necrotizing pneumonia from lip abscess: a case report. J Oral Maxillofac Surg. 2007;65(11):2350-3.

12. Lee JT, Hsiao HT, Tzeng SG. Facial necrotizing fasciitis secondary to accidental bite of the upper lip. J Emerg Med. 2011;41(1):e5-8.

13. Gozal D, et al. Necrotising fasciitis. Arch Surg. 1986;121:233.

14. Wong $\mathrm{CH}$, et al. The LRINEC (laboratory risk indicator for necrotizing fasciitis) score: a tool for distinguishing necrotizing fasciitis from other soft tissue infections. Crit Care Med. 2004;32(7):1535-41.

Submit your next manuscript to BioMed Central and we will help you at every step:

- We accept pre-submission inquiries

- Our selector tool helps you to find the most relevant journal

- We provide round the clock customer support

- Convenient online submission

- Thorough peer review

- Inclusion in PubMed and all major indexing services

- Maximum visibility for your research

Submit your manuscript at www.biomedcentral.com/submit
Biomed Central 